\title{
NORTH AMERICAN GEOLOGICAL INFORMATION SYSTEMS
}

by

Stein W. Bie and Goëtz Gabert

Computer-based information systems for geology and related earth sciences are still in the early stages of development in the U.S.A. and Canada. Some however, show promise both as scientific tools and as profitable economic investments. This is a brief preview of the basic conclusions drawn in a forthcoming publication on the various North American systems currently in use.*

\section{Energy Data Systems}

Based on our discussions with U.S. companies such as Phillips, Cities Service, Amoco and Gulf, as well as Home Oil, Amoco and Mobil in Canada, most oil companies have ventured into clectronic data processing (EDP) systems to support work in their geophysical and geological divisions. Strategy and experiences are highly varied. Senior management decisions strongly influence technical solutions and support given to smaller nuclei of scientists wishing to employ new tools. Some large companies have chosen standard data base management systems originally developed for administrative purposes, using mainly purchased applications software on large host computers. Smaller companies have commonly developed their own systems using sequential or index-sequential file organization on mini-computers.

Both groups report significant difficulties and costs associated with data "capture" of borehole information. Many rely extensively on the supply of digital data from scouting companics, such as the Petroleum Information Corporation's files, and use their standards. Simple, well structured input systems, distinctly different from traditional practice, are most successful.

\section{Mineral Data Systems}

U.S. and Canadian government organizations have been active in collecting data on mineral deposits and occurrences. Effort has been expended on developing input systems, file organization systems and different devices for presentation tailored to meet specific requirements.

Data capture from old and ill-structured records of varying quality forms a major problem for establishing retrospective data bases. Projects are underway to create files on mineral deposits and rock analyses (for example, uranium - U.S. Department of Energy in Grand Junction, Colorado; CRIB and RASS Files - USGS; a file index to Canadian mineral deposits - Canmindex - and Geochemical Data Files - GSC, Ottawa). Simple file organization systems have proven useful in the initial phases, but the use of commercial data base management systems (DBMS) is likely to increase in the near future. New and faster colour map presentation techniques (such as ink jet plotting) can greatly aid data analysis and map production. (Figure 1 is a monochrome produced by this technology; GSC's Map 15-1979 is an excellent example of a published colour map.)

Figure 1.

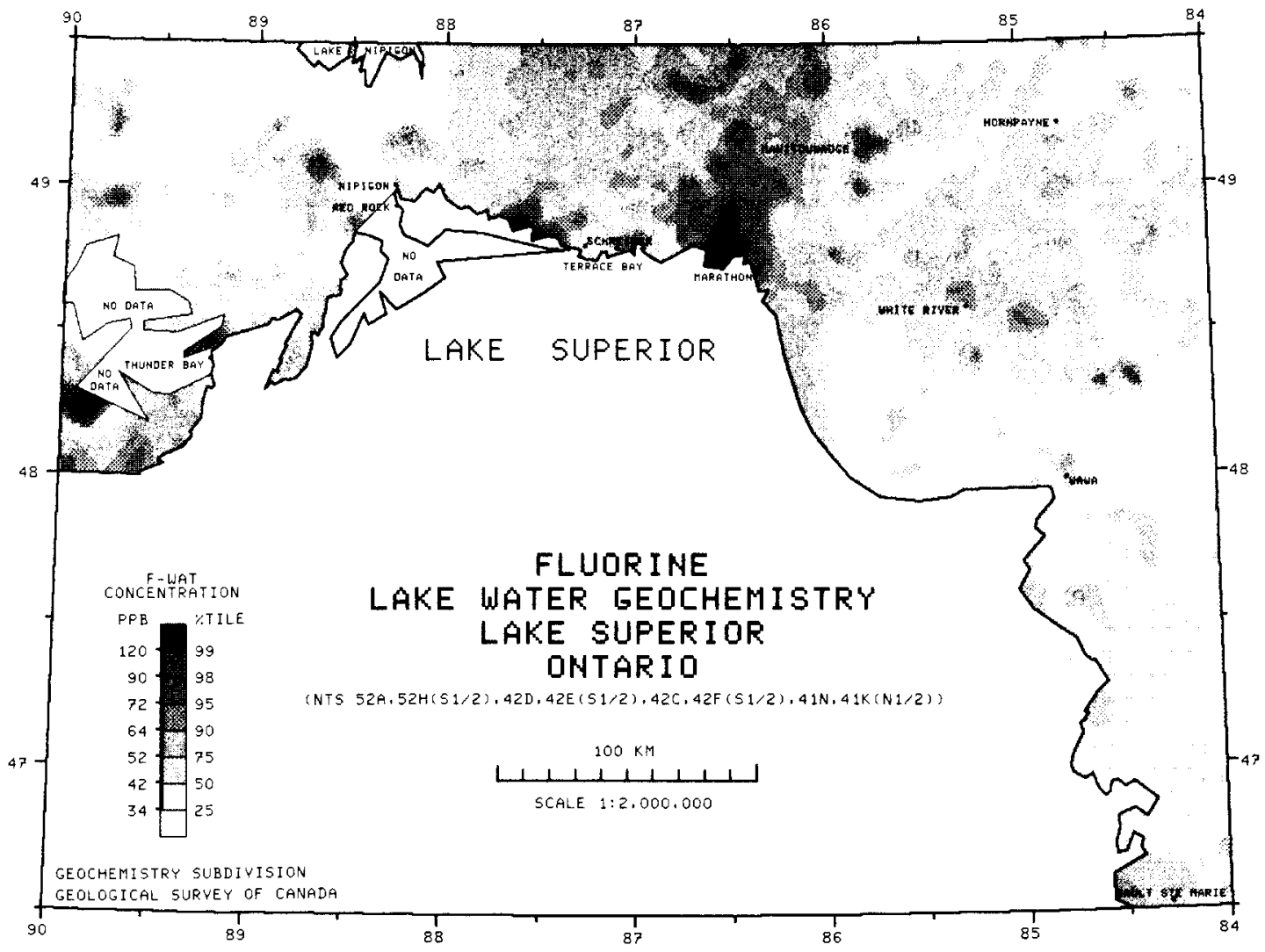

* This study was supported by the USGS, the GSC, the IUGS committee COGEODATA, the Norwegian Research Council on Science and Technology, the Norwegian Ministry of the Environment, and the authors' professional organizations. The final report is tentatively entitled "A Survey of North American Earth Sciences Information Systems in 1978-79". 
It appears that mineral exploration companies or consultants have been less active in establishing mineral data systems than those working in petroleum exploration.

\section{Geophysical Data Systems}

Numerical data handling is firmly established in geophysics as this sector of the scientific community has long relied on computing for data analysis and presentation. Direct digital data capture, or standard analogue-to-digital conversion, ease input problems. Both the private sector (oil companies and service bureaux for such analyses as well logging) and government institutions are well organized.

Major activity has been devoted to complex computations on large data sets in sequential files requiring a computer with a capability of handling efficiently this load of "numbercrunching". The current tendency is to use advanced DMBS (System 2000) to store earthquake and gravity data. Particularly impressive are the systems at the USGS in Denver, Colorado, and the Gravity Data Centre in Ottawa. Contour packages are extensively used for data presentation, but there is little comparative quality research on alternative digital terrain models for gravity data.

\section{Commodity Estimates}

Government policies have recently been concerned with commodity estimates of essential energy and mineral resources for national and international planning in economics.

Both the U.S. Bureau of Mines and the Department of Energy have major and impressive data collection and analysis programs for U.S. and international mineral and energy resources. The increasingly compulsory national reporting procedures have improved the quality and quantity of data submitted, and modern DBMS are commonly used. On a smaller scale, links between scientists and economists have been successfully developed for U.S. off-shore petroleum, U.S. federal coal reserves, minerals and coal availability in Canada and, recently, for private company planning (as with Kennecott, for example). Two methodological approaches were noted: a "complete coverage" strategy and an "indicator sampling" program, limiting smaller groups to the monitoring of key installations or producers.

\section{Physical Planning}

In the U.S.A., a number of USGS groups now employ cellbased computer overlay techniques to superimpose digital maps of different land characteristics for erosion prevention, earthquake forecasting and land planning. Similar systems are used by the local government in the San Francisco Bay area. It is seen as a useful way to provide geological data in a form readily available to planners.

Extensive upgrading of the land data system of the Lands Directorate in Environment Canada, Ottawa, now enables the system to provide interpretive maps for many planning purposes. Scanning, digitizing and interactive processing have led to the creation of large data bases now available for routine use. An analogous system, of more modern design, is under construction in the U.S. Bureau of Land Management in Denver, Colorado.

\section{ABOUT THE AUTHORS:}

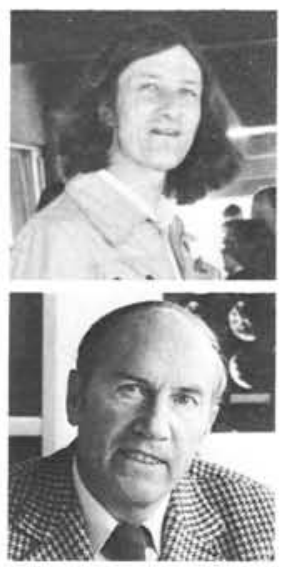

Stein W. Bie is with the Norwegian Computing Center in Oslo. He received his doctorate from Oxford University in soil survey and land systems mapping methodology, and has worked on surveys and survey methods in East Africa, Australia, Cyprus and the U.K.; between 1972 and 1977, he planned, designed and implemented a computer-based information system for soil, hydrological and geological data in the Netherlands. Dr. Bie is chairman of the COGEODATA's working group on data structures and data management.

EPISODES, Vol. 1980, No. 3

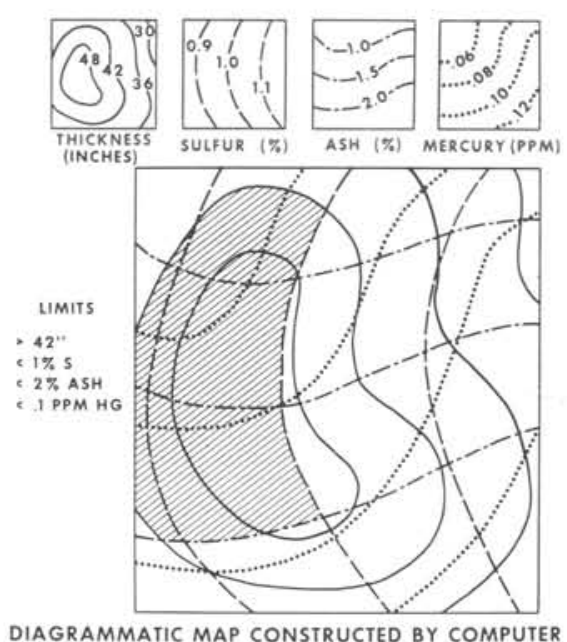

GARNET is a computer-based graphics system designed to aid the coal field geologists at the U.S. Geological Survey in preparing reports of the coal resources of the U.S.A. GARNET is the second component of the National Coal Resources Data System (NCRDS) and uses a variety of pointlocated data. An important objective of GARNET is to estimate the quality and quantity of coal under a variety of geologic, geochemical, economic and other conditions. This figure illustrates the kind of output GARNET produces using four data layers (thickness, sulphur, ash, and mercury content). The net area of available coal is shaded and indicates the quantity of coal available after the limits of each layer have been met. (Map taken from G. Gabert, 1980, "The U.S. National Coal Resources Data System (NCRDS)": COGEODATA Newsletter, vol. 6, 3, p. 28-31)

\section{Cartography}

In addition to extensive use of contouring packages for geophysical and geochemical data, computer-aided cartography is slowly gaining ground. Digitizing of manuscript maps constitutes a main bottleneck to progress. Economically attractive production of such things as multi-coloured geological maps is not universal. Falling hardware costs will lead to a change here.

The use of computer cartography as an analytical tool is strongly on the increase. These analyses often lead to the construction of derived maps (U.S. Soil Conservation Service, Land Resources Research Institute, Ottawa) which are proving particularly useful. Predominantly numerical automation of data on geochemistry and coal has been shown to have great potential (GSC, both in Ottawa and in Calgary).

\section{Miscellaneous Applications}

Data-about-data systems have been successful, both for map information (USGS, Reston), palynology (GSC, Ottawa) and in literature documentation for bibliographic data. For smaller data sets, relatively simple systems have proven equally successful, but when used for very large data sets (such as lunar samples) they are considerably more demanding on computing time.
A Director in the Geological Survey of the Federal Republic of Germany in Hannover, Dr. Goëtz Gabert specializes in computer applications in geology. He has carried out extensive geological work in developing countries, most recently for the ECA in establishing African Mineral Resource Development Centres (see EPISODES 1979, No. 3, pp. 9-11). Dr. Gabert is SecretaryTreasurer of the IUGS Commission on Storage. Automatic Processing and Retrieval of Geological Data (COGEODATA), and has just been appointed CGMW Continental Vice President: Europe. 